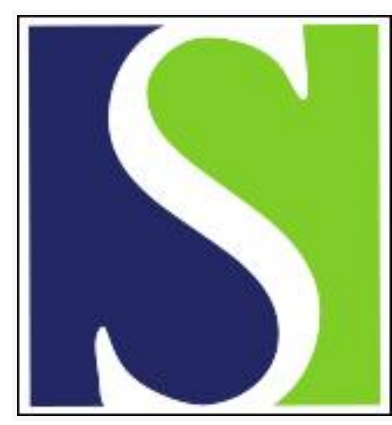

Scand J Work Environ Health 2004;30(3):249-252

https://doi.org/10.5271/sjweh.786

Issue date: Jun 2004

Mortality from chronic obstructive pulmonary disease and pleural mesothelioma in an area contaminated by natural fiber (fluoro-edenite)

by Biggeri A, Pasetto R, Belli S, Bruno C, Di Maria G, Mastrantonio M, Trinca S, Uccelli R, Comba P

Affiliation: Department of Statistics, University of Florence, Florence, Italy. pasetto@iss.it

Key terms: asbestiform fibers; chronic obstructive pulmonary disease; contamination; environmental exposure; fluoro-edenite; mortality; natural fiber; pleural mesothelioma; pleural neoplasms; respiratory disease; short communication

This article in PubMed: www.ncbi.nlm.nih.gov/pubmed/15250654 


\title{
Mortality from chronic obstructive pulmonary disease and pleural mesothelioma in an area contaminated by natural fiber (fluoro-edenite)
}

\author{
by Annibale Biggeri, MD, ${ }^{1}$ Roberto Pasetto, DSC, ${ }^{2}$ Stefano Belli, DSC, ${ }^{2}$ Caterina Bruno, MD, ${ }^{2}$ Giuseppe Di \\ Maria, MD, ${ }^{3}$ Marina Mastrantonio, DSC, ${ }^{4}$ Stefania Trinca, DSC, ${ }^{2}$ Raffaella Uccelli, DSC, ${ }^{4}$ Pietro Comba, \\ $P h D^{2}$
}

Biggeri A, Pasetto R, Belli S, Bruno C, Di Maria G, Mastrantonio M, Trinca S, Uccelli R, Comba P. Mortality from chronic obstructive pulmonary disease and pleural mesothelioma in an area contaminated by natural fiber (fluoro-edenite). Scand J Work Environ Health 2004;30(3):249-252.

\begin{abstract}
Objectives The purpose of the present study was to investigate the association between mortality from chronic obstructive pulmonary disease (COPD) and exposure to fluoro-edenite, a newly discovered amphibolic fiber found in Biancavilla (Sicily), a municipality on the slope of the Etna volcano, where a high mortality from malignant mesothelioma had been previously observed.

Methods Thirty-six municipalities located in the volcanic area of mount Etna were selected for study. An ecological regression model was applied with mortality from COPD as the dependent variable, mortality from mesothelioma as a proxy for exposure to fluoro-edenite, and lung cancer mortality, an urban-rural index, a deprivation index and an aging index as the predictors of COPD mortality. For each municipality, risk classes were determined for the continuous variables with the use of a finite mixture model.

Results A significant association was found between COPD mortality and pleural neoplasm mortality among the women in this study. The association was less consistent for the men.

Conclusions Despite the limitations of this ecological study, the results cohere with the results of toxicologic and observational studies and suggest an etiologic role for fluoro-edenite in nonmalignant respiratory diseases.
\end{abstract}

Key terms asbestiform fibers, environmental exposure, pleural neoplasms, respiratory disease.

In many places throughout the world, several cases of environmental exposure to natural asbestiform fibers have been described since the late 1970s. [For a recent review, see the report by Goldberg [Health effects of non occupational exposure to asbestos (Asbestos Health Effects Conference, Environmental Protection Agency (EPA) web site). May, 2001. Available at: http:// www.epa.gov/swerrims/ahec/. Accessed 15 December 2003]. The health effects related to such exposure are similar in each reported case (ie, a high incidence of malignant mesothelioma and a high prevalence of nonmalignant pleural lesions).

Subsequent to the detection of increased mortality from malignant pleural neoplasms in the rural municipality of Biancavilla, with a population of approximately 20000 people and located on the slopes of the Etna volcano in eastern Sicily, an asbestiform mineral fiber was detected in the local stone quarry and in materials used in buildings and road pavement (1). A crystal-chemistry investigation identified this mineral as fluoro-edenite, a new end-member of the edenite $\rightarrow$ fluoro-edenite series (2). Due to the similarities between fluoro-edenite and tremolite, fibrogenic activity in the respiratory system was hypothesized for this fiber.

A preliminary geographic mortality study was thus performed in which the observed mortality from nonmalignant respiratory disease and chronic obstructive pulmonary disease (COPD) in Biancavilla were compared with the expected figures provided for all other rural municipalities of the province of Catania. Our selection of municipalities with the same urban-rural category was motivated by the differences in mortality from respiratory disease reported in relation to the level of urbanization (3). The mortality pattern for nonmalignant

1 Department of Statistics, University of Florence, Florence, Italy.

2 Istituto Superiore di Sanità, Rome, Italy.

3 Department of Internal Medicine, University of Catania, Catania, Italy.

4 Italian National Agency for New Technology, Energy and Environment (ENEA), Rome, Italy.

Reprint requests to: Dr Roberto Pasetto, Laboratorio di Igiene Ambientale, Istituto Superiore di Sanità, Viale Regina Elena no 299, 00161 Rome, Italy. [E-mail: pasetto@iss.it] 
respiratory diseases in 1980-1997 showed a standardized mortality ratio (SMR) of 154 for Biancavilla [95\% confidence interval (95\% CI) 139-171), the corresponding figure for COPD being 164 (95\% CI 142-187). No diagnosis of pneumoconiosis or lung fibrosis was found on death certificates in Biancavilla because of a previous lack of awareness of fiber exposure (table 1). We thus assumed that a wider range of conditions may have been allocated to the category of obstructive disease. Furthermore, the etiology of COPD, a wide range of diseases characterized by chronic nonreversible airflow limitation and airway obstruction, is not well defined (4). Various risk factors can act either alone or synergistically (5). Upon these assumptions, we studied the geographic distribution of mortality from COPD and evaluated its association with some predictive variables using ecological regressions.

\section{Material and methods}

The following study design was adopted. Altogether 38 municipalities, including Biancavilla, whose soil consists of lavic material of recent or remote origin, were identified. The selection of the study area was based on the assumption that the mesothelioma cases related to fluoro-edenite exposure would be ascertained only for Biancavilla, but the geological and mineralogical processes of genesis of the fiber are not yet well known since the areas and stratum of fiber diffusion in the soil of the Etna volcano area have not been characterized (2). The town of Catania was excluded from the study because it is the largest urban setting in the area; another

Table 1. Standardized mortality ratio (SMR) from all causes, malignant pleural neoplasms, respiratory diseases, and chronic obstructive pulmonary disease (COPD) in Biancavilla versus other rural municipalities of the Catania district in 1980-1997. (95\% Cl $=95 \%$ confidence interval)

\begin{tabular}{lccc}
\hline Cause & Deaths $(\mathrm{N})$ & SMR & $95 \% \mathrm{Cl}$ \\
\hline All & & & \\
Women & 1644 & 107 & $102.4-113.8$ \\
Men & 1820 & 104 & $99.8-109.4$ \\
Total & 3464 & 106 & $102.2-109.3$ \\
Malignant pleural & neoplasms & & \\
Women & 7 & 724 & $289.9-1491$ \\
Men & 9 & 638 & $291.1-121.1$ \\
Total & 16 & 669 & $382-1086$ \\
Respiratory diseases & & \\
Women & 138 & 167 & $141.1-198.5$ \\
Men & 220 & 147 & $127.8-167.3$ \\
Total & 358 & 154 & $138.8-171.2$ \\
COPD & & & \\
Women & 79 & 200 & $158.2-249.1$ \\
Men & 137 & 144 & $121.3-170.9$ \\
Total & 216 & 163 & $142.4-186.8$ \\
\hline
\end{tabular}

municipality was excluded because mortality data were not available. The information collected for the $36 \mathrm{mu}-$ nicipalities and stored in a geographic information system (MapInfo software) was the following: mortality from 1 January1980 to 31 December 1997 for COPD [International Classification of Diseases, ninth revision (ICD-9) 4900-4940], malignant pleural neoplasms (ICD-9 1630 1639), lung cancer (ICD-9 1620-1629), urban-rural classification (2 categories), socioeconomic deprivation index (4 categories), and aging index (3 categories).

The urban-rural classification of municipalities was determined according to a procedure based on a set of variables collected in the national census carried out by the National Statistics Institute (ISTAT) (6). The socioeconomic deprivation index was also constructed from statistics of the national census, combining variables related to deprivation, such as proportion of subjects with low educational level, proportion of one-parent families, proportion of families who do not own their residence, proportion of the unemployed active population, and proportion of houses without an inside bath (7). The aging index was constructed as the ratio of people $>65$ years of age to those $0-14$ years of age. We controlled for age through indirect standardization (the province of Catania being the reference) for all the mortality indices used in the study. Mortality from COPD (standardized mortality ratio) formed the dependent variable, whereas the urban-rural and deprivation indices were included as predictors. They are associated with mortality from respiratory diseases and thus reflect the differences in smoking habits, occupational exposures, and air pollution. Furthermore the use of a socioeconomic deprivation index in studies of small areas is widely advised because such an index covers many confounding factors (8), and, specifically, a relationship has been reported between socioeconomic status and COPD (9). Mortality from malignant pleural neoplasms was used as an indirect indicator of exposure to fluoro-edenite. In addition an aging index was included because it reveals any relationship to birth cohort effects. We used mortality from lung cancer as an indirect indicator of smoking habits and occupational exposures. The likelihood ratio test was used to evaluate the heterogeneity of the relative risks for COPD in the respective areas using the negative binomial model (10). This model accounts for the Poisson random variability due to the small number of observed events and varying population sizes among the areas under study. The inclusion of mortality from lung cancer or pleural neoplasms as predictors required appropriate statistical filtering of the random variability of the observed and expected ratios. First, we estimated the following number of risk classes: three for lung cancer [relative risk (RR) 0.7 , frequency $27 \%$; RR 1.0, frequency $30 \%$; RR 1.14 , frequency 43\%] and two for pleural neoplasms (RR 0.9, frequency 
96\%; RR 4.0 frequency 4\%), and the class belonging to each municipality using a finite mixture model by means of CA MAN free software (Computer Assisted Analysis of Mixtures) (11); see Lindsay (12) for details on the joint estimation of the number of classes and the relative risk associated with each class. Second, we used the obtained classification in a subsequent negative binomial regression analysis of COPD mortality. This regression model is appropriate for extraPoisson variability, which usually arises with the use of small-area mortality data. Last, mortality from lung cancer was strongly associated with socioeconomic deprivation and the aging, whereas the latter was not significantly correlated with COPD. Therefore, to avoid the high instability related to the contemporary use of nearly collinear variables (lung cancer and socioeconomic deprivation) in the regression analyses for COPD mortality, we used these variables alternatively.

\section{Results}

A strong heterogeneity of mortality (standardized mortality ratio) from COPD was found among the municipalities [likelihood ratio test statistics with one degree of freedom being 94.0 for the men $(\mathrm{P}<0.001)$ and 60.1 for the women $(\mathrm{P}<0.001)]$. The highest average annual standardized mortality rates in the period 1980-1997 (direct method, reference population Italy 1991) were observed for the men (98.7 per 100000 ) and women (63.1 per 100000 ) in the municipalities of Nicolosi and Biancavilla, respectively.

Figure 1 shows the distribution of mortality from COPD in five risk categories determined using the finite mixture model.

The results of the multiple negative binomial regression analyses are shown in table 2. COPD mortality was significantly associated with residence in rural areas. For the women, a significant association with mortality from pleural neoplasms was found; the corresponding figure for the men was consistent, but with a wider confidence interval.

\section{Discussion}

The results of our study must be considered with caution, first because mortality from malignant pleural neoplasms in the studied region may also be associated with other exposures and, second, because, as in all epidemiologic studies based on aggregated data, the results may have been affected by the well known "ecological bias" (13). Despite these limitations, the finding of a significant association between COPD and pleural neoplasm mortality, when adjusted for urban-rural gradient and lung cancer mortality, is strongly suggestive of an etiologic role of fluoro-edenite exposure in the occurrence of nonmalignant respiratory diseases. Indirect

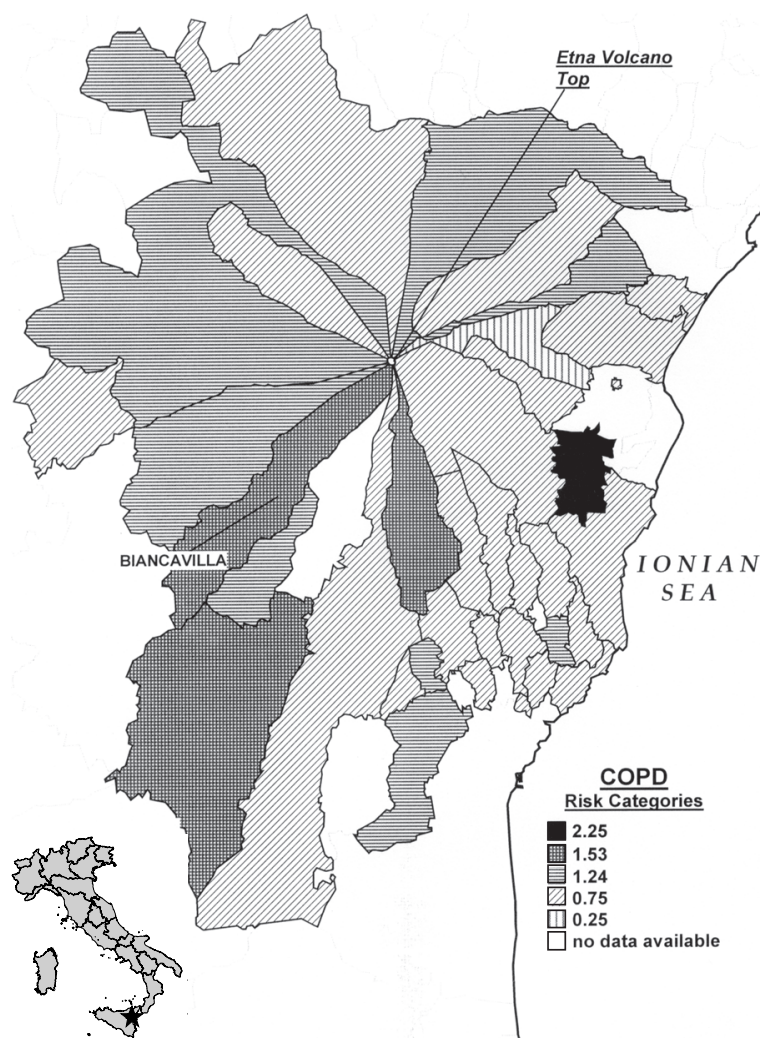

Figure 1. Risk categories of mortality from COPD in the municipalities of the study area.

Table 2. Gender-specific relative risks (RR) and their 95\% confidence intervals $(95 \% \mathrm{Cl}$ ) for chronic obstructive pulmonary disease in relation to the unit increase by selected risk factors associated with the ecological regression results, socioeconomic deprivation being an alternative to lung cancer in the model.

\begin{tabular}{|c|c|c|c|c|c|c|c|c|}
\hline \multirow[t]{2}{*}{ Gender } & \multicolumn{2}{|c|}{ Pleural neoplasm } & \multicolumn{2}{|c|}{ Lung cancer } & \multicolumn{2}{|c|}{ Deprivation ${ }^{a}$} & \multicolumn{2}{|c|}{ Urban-rural b } \\
\hline & $\mathrm{RR}$ & $95 \% \mathrm{Cl}$ & $\mathrm{RR}$ & $95 \% \mathrm{Cl}$ & $\mathrm{RR}$ & $95 \% \mathrm{Cl}$ & $\mathrm{RR}$ & $95 \% \mathrm{Cl}$ \\
\hline Men & 1.11 & $0.97-1.29$ & 1.83 & $0.92-3.64$ & 1.10 & $1.01-1.20$ & 1.32 & $1.04-1.69$ \\
\hline Women & 1.23 & $1.07-1.42$ & 0.89 & $0.42-1.88$ & 1.05 & $0.95-1.17$ & 1.57 & $1.18-2.08$ \\
\hline Total & 1.20 & $1.00-1.44$ & 2.07 & $0.93-4.62$ & 1.10 & $0.98-1.23$ & 1.34 & $1.02-1.77$ \\
\hline
\end{tabular}

a Less-deprived category taken as reference.

b Urban feature taken as reference. 
support of this hypothesis was recently provided by the results of in vitro toxicity studies $(14,15)$ and by the observation of the presence of the fiber in the sputum of bronchitis patients (MG Putzu, personal communication). Our findings are consistent with previous results showing that the standardized mortality ratios for pleural neoplasms in Biancavilla in 1980-1997 were higher for the women than for the men (table 1). Furthermore, the gender ratio (men:women) for COPD mortality in the $>65$-year group was 1.6 (95\% CI 1.3-1.9) for Biancavilla and 2.2 (95\% CI 2.1-2.3) for the other municipalities in the study area. In the same years and age group the mean annual standardized mortality rate for COPD in Biancavilla was 558 per 100000 for the men and 301 per 100000 for the women, while the same figures for the other municipalities of the study area were 387 and 143, respectively. This observation may reflect a higher level of fiber exposure for women, who are often engaged in activities such as the sweeping of dwellings and sidewalks. Similarly, a higher mortality rate has recently been reported for mesothelioma among women than among men in Turkish villages where the whitewashing of homes with asbestos-contaminated soil (16) is a common job of women. Differences in alveolar deposition at the same level of fiber exposure may, however, also be related to gender-associated factors like respiration patterns, lung volume, and body size (17). In light of the findings of our study, a clinical investigation of the prevalence of lung fibrosis and pleural plaques among female residents of Biancavilla is warranted.

\section{Acknowledgments}

The authors wish to thank Professor Francesco Burragato from the Department of Earth Sciences of the La Sapienza University in Rome for the map of lavic soils, Dr Alessandra Binazzi from ENEA for her cooperation in the mortality data management, and Dr Francesco Forastiere from the Department of Epidemiology of the Rome-E Local Health Authority for his qualified advice and helpful comments.

\section{References}

1. Paoletti L, Batisti D, Bruno C, Di Paola M, Gianfagna A, Mastrantonio M, et al. Unusually high incidence of malignant pleural mesothelioma in a town of eastern Sicily: an epidemiological and environmental study. Arch Environ Health 2000;55:392-8.
2. Comba P, Gianfagna A, Paoletti L. Pleural mesothelioma cases in Biancavilla are related to a new fluoro-edenite fibrous amphibole. Arch Environ Health 2003;58:229-32.

3. Uccelli R, Mastrantonio M, Di Paola M. Distribuzione delle cause di morte in comuni a diverso grado di urbanizzazione [Distribution of causes of death in municipalities with different degrees of urbanisation]. Epidemiol Prev 2000;24:28-37.

4. Siafakas NM, Vermeire P, Pride NB, Paoletti P, Gibson J, Howard $\mathrm{P}$, et al. Optimal assessment and management of chronic obstructive pulmonary disease (COPD): ERS consensus statement. Eur Respir J 1995;8:1398-420.

5. Viegi G, Scognamiglio A, Baldacci S, Pistelli F, Carrozzi L. Epidemiology of chronic obstructive pulmonary disease (COPD). Respiration 2001;68:4-19.

6. Istituto Centrale di Statistica (ISTAT). Classificazione dei comuni secondo le caratteristiche urbane e rurali [Classification of municipalities by urban-rural characterization]. Rome: ISTAT; 1986. Note e relazioni $\mathrm{n} 2$.

7. Cadum E, Costa G, Biggeri A, Martuzzi M. Deprivazione e mortalità: un indice di deprivazione per l'analisi delle disuguaglianze su base geografica. [Deprivation and mortality: a deprivation index suitable for geographical analysis of inequalities]. Epidemiol Prev 1999;23:175-87.

8. St Leger S, editor. Use of deprivation indices in small areas studies of environment and health. J Epidemiol Community Health 1995;49 Suppl 2:1-88.

9. Prescott E, Godtfredsen N, Vestbo J, Osler M. Social position and mortality from respiratory diseases in males and females. Eur Respir J 2003;21:821-6.

10. Martuzzi M, Hills M. Estimating the degree of heterogeneity between event rates using likelihood. Am J Epidemiol 1995;141:369-74.

11. Böhning D. Computer assisted analysis of mixtures and applications: meta analysis, disease mapping and others. Boca Raton (FL): Chapman \& Hall, CRC Press; 1999.

12. Lindsay BG. Mixture models: theory, geometry and applications. Hayward (CA): Institute of Mathematical Statistics; 1995. NSF-CBMS regional conference series in probability \& statistics, vol 5.

13. Morgenstern H. Ecologic studies. In: Rothman KJ, Greenland S, editors. Modern epidemiology. 2nd edition. Philadelphia (PA): Lippicott-Raven Publishers; 1998. p 469-71.

14. Travaglione S, Bruni B, Falzano L, Paoletti L, Fiorentini C. Effects of the new-identified amphibole fluoro-edenite in lung epithelial cells. Toxicol In Vitro 2003;17:547-52.

15. Rapisarda V, Amati M, Coloccini S, Bolognini L, Gobbi L, Duscio D. In vitro hydroxyl radical (HO) generation from dust containing fluoro-edenite in volcanic rock in Biancavilla (Eastern Sicily). Med Lav 2003;94:200-6.

16. Metintas S, Metintas M, Ucgun I, Oner U. Malignant mesothelioma due to environmental exposure to asbestos. Chest 2002; 122:2224-9.

17. Smith DD. Women and mesothelioma. Chest 2002;122: 1885-6.

Received for publication: 6 October 2003 